

\title{
Personalidade da marca de destinos, fontes de informações e sua relação com o critério de escolha da chapada das mesas por parte dos turistas
}

Personality of the destination brand, information sources and its relation to the criteria for choosing the plateau of the tables by tourists

Evellyn Christynne de Souza Sampaio

Estudante no curso Técnico em Administração pelo Instituto Federal de Educação, Ciência e Tecnologia do Maranhão - IFMA, Porto Franco/MA, Brasil

E-mail: christy.harley7@gmail.com

\section{Lindemberg Costa Júnior}

Docente efetivo do Instituto Federal de Educação, Ciência e Tecnologia do Maranhão IFMA, Porto Franco/MA, Brasil

E-mail: lindemberg.junior@ifma.edu.br

Artigo recebido em: 31-12-2020

Artigo aprovado em: 07-04-2021 


\section{RESUMO}

Este estudo tem como objetivo identificar o critério de escolha de turistas ao decidir pela Chapada das Mesas, bem como perceber a relação entre o critério de escolha dos turistas e a personalidade da marca de destinos; verificar os traços que constituem a personalidade da marca de destinos na visão de turistas; e identificar o grau de relevância de diferentes fontes de informações utilizadas por turistas na busca por um destino turístico. A Chapada das Mesas está localizada no Estado do Maranhão, havendo a cidade de Carolina como base para explorar as belezas da região. Adotou-se metodologia quantitativa, com caráter descritivo e corte transversal. Neste contexto, optou-se pela coleta primária de dados utilizando o formulário eletrônico Google Forms. Os resultados sugerem que a Chapada das Mesas é um local excitante, muito por conta da beleza do local. Para buscar maiores informações sobre o local de destino, os turistas procuram a opinião de amigos e familiares e também de pessoas confiáveis que já visitaram o local. Revela-se ainda que a internet é um importante canal de informação, pois pode-se ver as fotos e comentários de turistas com experiência previa do local.

Palavras-chave: Marketing Turístico. Personalidade da Marca. Consumidor de Turismo.

\section{ABSTRACT}

This study aims to identify the criteria for choosing tourists when deciding on Chapada das Mesas, as well to understand the relationship between the criteria for choosing tourists and the personality of the destination brand; verify the traits that chose the personality of the destination brand in the view of tourists; and to identify the degree of enterprise of different sources of information used by tourists in the search for a tourist destination. Chapada das Mesas is located in the State of Maranhão, with the city Carolina as a base to explore the beauties of the region. Quantitative methodology was adopted, with a descriptive and crosssectional character. In this context, we opted for primary data collection using the electronic form Google Forms. The results obtained at Chapada das Mesas is an exciting place, largely because of the beauty of the place. To seek more information about the destination, tourists seek the opinion of friends and family and also of people who have already rated the place. It is also revealed that an internet is an important information channel, as it can be seen as photos and comments from tourists with previous experience of the place.

Keywords: Tourism Marketing. Brand Personality. Tourism Consumer. 


\section{INTRODUÇÃO}

Nas últimas décadas os negócios foram moldados de acordo com as tendências que a sociedade imprimia, bem como a globalização e avanço constante das tecnologias (Costa Junior \& Silva, 2020). Desta forma, possibilitou-se o aumento da concorrência, forçando os gestores a adotarem planejamentos com a intenção de minimizar as ameaças e realçar as oportunidades (Hosany, Ekinci \& Uysal, 2006). No setor de turismo o cenário não é diferente, os gestores tiveram que pensar de maneira estratégica para permitir a análise do cenário e tomar as decisões corretas para permanecer no mercado (Ekinci \& Hosany, 2006; Pimentel, Pinho \& Vieira, 2006; Aguilar, Guillén \& Roman, 2016).

Como os demais setores comerciais, uma das estratégias utilizadas pelo segmento de turismo é a adoção das ferramentas de branding (Costa Junior \& Silva, 2020; Sahin \& Baloglu, 2011). Acredita-se que os destinos turísticos possuem características parecidas, contudo, os turistas podem ser atraídos por alguma variável em particular, bem como se afastar da opção por outra variável específica (Kubo, Costa, Cardoso \& Ribeiro, 2017; Manosso, Ruiz \& Nakatani, 2020). Desta forma, é necessário conhecer o publico alvo e o que atrai os turistas (Hultman, Skarmeas, Oghazi \& Beheshti, 2015).

Neste contexto, encontrou-se estudos relacionados à temática de turismo e marcas de destino. Cita-se como exemplo as pesquisas de Chen e Pou (2013); Costa Júnior e Silva (2020); Ekinci e Hosany (2006); Hosany, Ekinci e Uysal (2007); Hultman et al. (2015); Kubo et al. (2017); Kumar (2016); Li e Kaplanidou (2013); Manosso, Ruiz e Nakatani (2020); Murphy, Benckendorff e Moscardo (2007); Papadimitriou, Apostolopoulou e Kaplanidou (2015); Sahin e Baloglu (2011); Shin, Yang, Nam e Koo (2017).

Com a intenção de avançar os estudos, a presente pesquisa propõe responder o seguinte questionamento: Qual é o critério de escolha de turistas ao decidir pela Chapada das Mesas? Para responder esta pergunta, o objetivo principal deste estudo é identificar o critério de escolha de turistas ao decidir pela Chapada das Mesas. Apresenta-se ainda os objetivos específicos: perceber a relação entre o critério de escolha dos turistas e a personalidade da marca de destinos; verificar os traços que constituem a personalidade da marca de destinos na visão de turistas; e identificar o grau de relevância de diferentes fontes de informações utilizadas por turistas na busca por um destino turístico (Costa Junior \& Silva, 2020).

Neste sentido, o presente estudo justifica-se teoricamente por acrescentar na literatura estudos sobre marketing turístico, marca de destinos, personalidade da marca de destinos turísticos e fontes de informações sobre destinos. O turismo pode ser encarado como um 
produto, e como tal, possui características de qualidade que podem servir como uma base na escolha do consumidor, no caso, o turista (Aguilar, Guillén \& Roman, 2016; Caldwell \& Freire, 2004). Como justificativa prática, o estudo proporciona aos gestores informações que possam subsidiar no processo decisório (Costa Junior \& Silva, 2020).

O objetivo principal deste estudo é identificar o critério de escolha de turistas ao decidir pela Chapada das Mesas. Em particular, a presente pesquisa possui três objetivos específicos: perceber a relação entre o critério de escolha dos turistas e a personalidade da marca de destinos; verificar os traços que constituem a personalidade da marca de destinos na visão de turistas; e identificar o grau de relevância de diferentes fontes de informações utilizadas por turistas na busca por um destino turístico.

Portanto, para alcançar o objetivo deste estudo, pesquisou-se estudos anteriores relacionados ao marketing turístico, personalidade da marca de destinos e fontes de informações sobre destinos turísticos. Em seguida, apresenta-se a metodologia utilizada. Logo após analisou-se os dados coletados, onde realizou-se a caracterização da amostra, estatística descritiva e regressão linear múltipla. E por fim, foram apresentados os achados e as conclusões da pesquisa.

\section{REFERENCIAL TEÓRICO}

\subsection{Marketing turístico}

A atividade turística é uma das mais importantes no setor econômico e da geração de emprego e renda (Costa Junior \& Silva, 2020). Segundo a autora, o setor representa 7,9\% do PIB nacional, sendo responsável por 6,59 milhões de empregos. Fator que está de acordo com Santana (2008), que afirma que o mercado turístico doméstico aumentou significativamente após a reestruturação da economia brasileira que teve início em 1994

Nesse sentido, Marketing turístico, segundo Krippendorf (1989) é a adaptação sistemática e coordenada da política das empresas de turismo, visando à plena satisfação das necessidades de determinados grupos de consumidores, obtendo com isso, um lucro apropriado. $\mathrm{O}$ autor também afirma que o ser humano não nasceu turista, mas sua curiosidade e a necessidade de mobilidade o fizeram um viajante, buscando desbravar, descobrir, aprender, lazer, e a fuga do massificante dia-a-dia de trabalho e da monotonia do cotidiano.

O ser humano precisa de momentos de lazer em que ele possa ter uma fuga de sua vida cotidiana, e ao mesmo tempo lhe seja proporcionada uma experiência de estranhamento, pois 
lembranças e vivências passadas serão ressignificadas nesse indivíduo (Pezzi \& Santos, 2012).

Nesse contexto, Huybers (2003) e Papadimitriou, Apostolopoulou e Kaplanidou (2015) afirmam que a escolha de um destino é determinada pela avaliação dos turistas dos atributos do destino e pela utilidade atribuída pelos turistas. Smith (1989) corrobora com essa afirmação ao mencionar sobre os fatores "push", que são formados a partir do turista, como, por exemplo, poder econômico, necessidades de viagens, motivações de viagens, comportamentos formais e informações em relação a viagens e grau de exposição às informações turísticas.

Entretanto, o marketing está acima de todos os critérios de escolha, com o uso da linguagem sedutora do discurso da mídia para divulgação do turismo, utilizando um conjunto de códigos e signos, que têm o poder de agrupar os atores que buscam a paz e a felicidade em outro lugar (Phillips, Lawrence \& Hardy, 2004). Além disso, como bem enfatiza Middleton e Clarke (2002) a nova tecnologia pode reduzir drasticamente o custo com marketing e distribuição, trazendo aumentos significativos de 20-30\% da movimentação do custo para se fazer uma venda.

Diante do exposto, acredita-se que as ferramentas do marketing turístico podem auxiliar os profissionais da área na tomada de decisões, bem como possibilita conhecer o perfil do seu público alvo (Costa Junior \& Silva, 2020). Neste sentido, no subcapítulo a seguir será relatada a importância da personalidade da marca de destinos como uma vantagem estratégica no processo de conquistar o turista.

\subsection{Personalidade da marca de destino}

A imagem do destino turístico costuma ser definida como o conjunto de crenças, ideias e visões de uma pessoa sobre um destino (Crompton, 1979), são uma construção psicológica desenvolvida pelo turista a partir de impressões ou de informações do destino (Kubo et al., 2017; Tasci \& Gartner, 2007).

Como um dos principais fatores de atração, promove uma relação com o turista, a qual de acordo com Jenkins (1999) apresenta certa complexidade. Tal como posição e relação afetiva do turista sobre seu destino (Silva \& Costa Junior, 2020; Mazzon \& Vera, 2008). Para análise desta complexidade, estudos têm usado um mapa de importância-desempenho avaliando dimensões funcionais e afetivas percebidas pelos turistas (Caldwell \& Freire, 2004). Segundo os autores, existem quatro principais percepções: 


\begin{tabular}{|l|l|}
\hline \multicolumn{1}{|c|}{ Quadro 1 - Dimensões funcionais e afetivas percebidas pelo turista } \\
\hline Quanto maior a representatividade do destino & \multicolumn{1}{c|}{ FUNCIONALIDADE } \\
\hline Quanto maior a representatividade do destino & Menor a funcionalidade do serviço \\
\hline Quanto menor a representatividade do destino & Maior a funcionalidade do serviço \\
\hline Quanto menor a representatividade do destino & Menor a funcionalidade do serviço. \\
\hline
\end{tabular}

Fonte: Caldwell e Freire, 2004.

Segundo Echtner e Ritchie (2003), a imagem se constitui tanto das percepções de atributos individuais de um produto, como também de percepções totais e holísticas. Além da satisfação em relação à infraestrutura, serviços e produtos disponíveis para compra (Heung \& Cheng, 2000; Costa Junior \& Silva, 2020).

A marca do destino e a imagem da marca devem ser bem trabalhadas pelos gestores para transmitir a identidade do local ao público (Pimentel, Pinho \& Vieira, 2006). De acordo com a afirmação, Jenkins (1999) afirma que entender as diferentes imagens de um destino contribui positivamente para as estratégias de marketing a serem planejadas.

Nesse sentido, a imagem é o principal fator de sucesso do destino turístico, e deve ser trabalhado pelo marketing do local (Rainisto, 2003). O grau de satisfação do turista depende da comparação entre a expectativa prévia decorrente de uma imagem pré-estabelecida, com o desempenho percebido no local escolhido (Costa Junior \& Silva, 2020; Pike, 2002).

Nesse contexto foram identificadas na literatura, escalas capazes de analisar a personalidade da marca, proporcionando a análise da marca de destinos turísticos em diferentes localidades (Aaker, 1997; Hosany, Ekinci, \& Uysal, 2006; Ekinci, Sirakaya-Turk \& Baloglu, 2007; Kumar, 2016). Apresentam-se os estudos no quadro 2: 
Quadro 2 - Escalas que medem a personalidade da marca de destinos

\begin{tabular}{|l|l|l|}
\hline \multicolumn{1}{|c|}{ Dimensão } & \multicolumn{1}{|c|}{ Escala } & \multicolumn{1}{|c|}{ Autores } \\
\hline Sofisticação & $\begin{array}{l}\text { Glamouroso; direcionado ao público classe A; boa } \\
\text { aparência; charme. }\end{array}$ & Aaker (1997) \\
\hline Robustez & Difícil acesso; traços ocidentais; atrações ao ar livre. & Aaker (1997) \\
\hline Excitação & Emocionante; ousado; original. & Hosany; Ekinci e Uysal (2006) \\
\hline Convivialidade & Amigável; hospitaleiro; orientado para a família. & $\begin{array}{l}\text { Ekinci, Sirakaya-Turk e } \\
\text { Baloglu (2007) }\end{array}$ \\
\hline Ferocidade & Violento; depravado; vulgar. & Kumar (2016) \\
\hline Conformidade & $\begin{array}{l}\text { Orientação religiosa do local; orientação política do } \\
\text { local; cultura do local. }\end{array}$ & Kumar (2016) \\
\hline
\end{tabular}

Fonte: Adaptado de Costa Junior e Silva, 2020.

\subsection{Fontes de informações sobre destinos turísticos}

A identidade de um destino é construída a partir das características que contribuem para a distinção e para a singularidade do destino por parte do turista (Llodrà-Riera, MartínezRuiz, Jiménez-Zarco, \& Izquierdo-Yusta, 2015; Melo \& Farias, 2014). Para Santana (2008) a imagem de um lugar é obtida a partir de experiências pessoais ou de informações secundárias, como conversas com amigos e familiares, mídia, programas de marketing, que divulguem o local e promoções, etc.

Diante de relações pessoais a escolha de um destino turístico, a primeira imagem é formada de acordo com a opinião de amigos e familiares (Pimentel, Pinho \& Vieira, 2006). Flores, Cavalcante e Raye (2012) afirmam que canais de comunicação, como os jornais, televisão e Internet, interferem diretamente no perfil dos turistas, pois o acesso mais rápido a tipos diversos de informação e facilidades faz com que estes turistas se tornem cada vez mais exigente em relação aos produtos e serviços que desejam.

A identidade de um destino, caracterizada por sua marca, se torna importante, pois os potenciais visitantes tomam suas decisões considerando também a confiança que construíram a partir da percepção que foi construída sobre o local (Mihailovich, 2006). Basicamente, os mesmos são influenciados por narrações e por imagens projetadas em mídias (Costa Junior \& Silva, 2020; Melo \& Farias, 2014).

Nesse contexto, sugere-se que as fontes de informações são passos iniciais no processo de escolha dos turistas por um destino, permitindo ao mesmo identificar características importantes do local, e fornecendo informações que possam subsidiar a decisão dos turistas (Llodrà-Riera et al., 2015; Costa Junior \& Silva, 2020). 


\section{METODOLOGIA}

Utilizou-se de metodologia quantitativa, com caráter descritivo e corte transversal com o objetivo de identificar o critério de escolha de turistas ao decidir pela Chapada das Mesas, bem como perceber a relação entre o critério de escolha dos turistas e a personalidade da marca de destinos; verificar os traços que constituem a personalidade da marca de destinos na visão de turistas; e identificar o grau de relevância de diferentes fontes de informações utilizadas por turistas na busca por um destino turístico (Costa Junior \& Silva, 2020).

Com a intenção de ouvir os turistas que foram ou pretendem ir as Chapadas das Mesas, adotou-se coleta primária de dados utilizando o formulário eletrônico Google forms. O questionário foi divulgado por WhatsApp, Direct e a rede social Instagram. Portanto, classifica-se a amostra como não probabilística por acessibilidade. A coleta de dados estendeu-se pelos meses de agosto, setembro, outubro, novembro e dezembro do ano de 2019 , e nos meses janeiro e fevereiro do ano de 2020.

O questionário foi desenvolvido com trinta e duas perguntas, utilizando-se da Escala de Likert composta por cinco posições. As questões se subdividem a partir do conhecimento e interesse no destino turístico chapada das mesas em: Convivialidade (Ekinci, Sirakaya-Turk, \& Baloglu, 2007), Excitação (Hosany, Ekinci, \& Uysal, 2006), Sofisticação, Robustez (Aaker, 1997), Ferocidade e Conformidade (Kumar, 2016). A escala foi utilizada no estudo de Costa Junior e Silva (2020), onde os autores analisaram o critério de escolha de turistas brasileiros ao decidirem por um destino para passarem suas férias.

Adicionou-se também: pergunta controle com o objetivo de identificar se o respondente já viajou ou pretende viajar para a Chapada das Mesas; Variável Y, onde $\mathrm{Y}=$ Como turista me considero criterioso na escolha de um destino turístico; afirmações que tem como objetivo identificar quais fontes de informações o turista leva em consideração para escolher um destino (Llodrà-Riera et al., 2015) e características sociodemográficas dos turistas. Apresenta-se o questionário de acordo com o quadro 3. 
Quadro 3 - Questionário utilizado para coletar os dados

\begin{tabular}{|c|c|}
\hline Dimensões & Afirmações \\
\hline Variável Y & 1. Como turista me considero criterioso na escolha de um destino turístico; \\
\hline Convivialidade & $\begin{array}{l}\text { 2. Eu escolho o meu destino turístico pelo fato dele ser seguro; } \\
\text { 3. Eu escolho o meu destino turístico por ele ser hospitalar; } \\
\text { 4. Eu escolho o meu destino turístico por ele possuir uma orientacão familiar; }\end{array}$ \\
\hline Excitação & $\begin{array}{l}\text { 5. Eu escolho o destino turístico pelo fato dele ser emocionante; } \\
\text { 6. Eu escolho meu destino turístico pelo fato dele ser ousado; } \\
\text { 7. Eu escolho meu destino turístico pelo fato dele ser original; }\end{array}$ \\
\hline Sofisticação & $\begin{array}{l}\text { 8. Eu escolho meu destino turístico pelo fato dele ser glamouroso; } \\
\text { 9. Eu escolho meu destino turístico pelo fato dele ser direcionado ao público } \\
\text { Classe A; } \\
\text { 10. Eu escolho meu destino turístico pela aparência da região; } \\
\text { 11. Eu escolho meu destino turístico pelo fato dele ser encantador; }\end{array}$ \\
\hline Robustez & $\begin{array}{l}\text { 12. Eu escolho meu destino turístico pelo fato dele ser um local de difícil acesso; } \\
\text { 13. Eu escolho destino turístico que possua traços ocidentais; } \\
\text { 14. Eu escolho destino turístico que tenha atrocões ao ar livre; }\end{array}$ \\
\hline Ferocidade & $\begin{array}{l}\text { 15. Eu escolho meu destino turístico pelo fato dele ser violento; } \\
\text { 16. Eu escolho meu destino turístico pelo fato dele ser depravado; } \\
\text { 17. Eu escolho meu destino turístico pelo fato dele vulgar; }\end{array}$ \\
\hline Conformidade & $\begin{array}{l}\text { 18. Eu escolho meu destino turístico pela orientação religiosa do local; } \\
\text { 19. Eu escolho meu destino turístico pela orientação política do local; } \\
\text { 20. Eu escolho meu destino turístico pela cultura do local; }\end{array}$ \\
\hline $\begin{array}{l}\text { Fontes de } \\
\text { Informação }\end{array}$ & $\begin{array}{l}\text { 21. Intermediários (agências de viagens ou operadores turísticos) } \\
\text { 22. Mídia especializada em turismo; } \\
\text { 23. Guias de viagem; } \\
\text { 24. Documentários; } \\
\text { 25. Amigos e conhecidos; } \\
\text { 26. Internet. }\end{array}$ \\
\hline
\end{tabular}

Fonte: Adaptado de Aaker (1997); Ekinci e Hosany (2006); Ekinci, Sirakaya-Turk e Baloglu (2007); Kumar (2016); Llodrà-Riera et al. (2015).

Nesse sentido, obteve-se um total de 193 respostas. Não obstante, após validar os questionários de acordo com a pergunta controle, obteve-se um total de 188 respondentes. Para analisar os dados realizou-se a caracterização da amostra, estatística descritiva e regressão linear múltipla. Utilizando-se modelo abaixo:

Modelo 1: Critério de seleção $=\beta_{0+} \sum_{i=1}^{6} \beta i X i+$ Controles $+E_{1}$

em que:

$\mathrm{X} 1$ = Convivialidade;

X2 = Excitação;

X3 = Sofisticação;

X4 = Robustez;

$\mathrm{X} 5$ = Ferocidade;

$\mathrm{X} 6$ = Conformidade;

Controles: gênero, idade, renda, quantas viagens realiza por ano e o quanto gosta de viajar;

$\mathrm{E} 1=$ Termo de erro. 


\section{ANÁLISE DOS DADOS}

\subsection{Caracterização da amostra}

Com o objetivo de identificar o critério de escolha de turistas ao decidir pela Chapada das Mesas, obteve-se um total de 188 respostas de turistas que querem ou já viajaram para a Chapada das Mesas. Nesse contexto, apresentam-se na tabela 1 as características sociodemográficas em relação a gênero, idade, renda familiar, viagens com fins turísticos por ano e o quanto gosta de viajar.

Tabela 1 - Características dos turistas brasileiros

\begin{tabular}{|c|c|c|}
\hline & \multicolumn{2}{|c|}{ CLIENTES } \\
\hline GÊNERO & $\mathbf{N}^{\mathbf{0}}$ & $\%$ \\
\hline Masculino & 83 & 44,14 \\
\hline Feminino & 105 & 55,85 \\
\hline Total & 188 & 100 \\
\hline \multicolumn{3}{|l|}{ IDADE } \\
\hline 18 a 25 anos & 137 & 72,82 \\
\hline 26 a 35 anos & 19 & 10,10 \\
\hline 36 a 45 anos & 21 & 11,17 \\
\hline 46 a 55 anos & 7 & 3,72 \\
\hline 56 anos ou mais & 4 & 2,12 \\
\hline Total & 188 & 100 \\
\hline \multicolumn{3}{|l|}{ RENDA FAMILIAR } \\
\hline Até $\mathrm{R} \$ 999,99$ reais & 59 & 31,38 \\
\hline Entre $\mathrm{R} \$ 1000,00$ e $\mathrm{R} \$ 2999,99$ & 59 & 31,38 \\
\hline Entre $\mathrm{R} \$ 3000,00$ e $\mathrm{R} \$ 4999,99$ & 40 & 21,27 \\
\hline Entre $\mathrm{R} \$ 5000,00$ e $\mathrm{R} \$ 7999,99$ & 17 & 9,04 \\
\hline Mais que $\mathrm{R} \$ 8000,00$ & 13 & 6,91 \\
\hline Total & 188 & 100 \\
\hline \multicolumn{3}{|c|}{ VIAGENS COM FINS TURÍSTICOS POR ANO } \\
\hline 01 viagem & 116 & 61,70 \\
\hline 02 viagens & 36 & 19,14 \\
\hline 03 viagens & 17 & 9,04 \\
\hline 04 viagens & 5 & 2,65 \\
\hline 05 ou mais viagens & 14 & 7,44 \\
\hline Total & 188 & 100 \\
\hline \multicolumn{3}{|c|}{ O QUANTO GOSTA DE VIAJAR } \\
\hline Não gosto & 5 & 2,65 \\
\hline Não gosto parcialmente & 2 & 1,06 \\
\hline Indiferente & 7 & 3,72 \\
\hline Gosto parcialmente & 41 & 21,80 \\
\hline Gosto muito & 133 & 70,4 \\
\hline Total & 188 & \begin{tabular}{|l|}
100 \\
\end{tabular} \\
\hline
\end{tabular}

Fonte: Dados da pesquisa, 2020.

De acordo com tabela 1, percebe-se uma pequena diferença em relação ao gênero, a qual os homens representam 44,14\% da amostra, e as mulheres representam 55,85\%. 
Majoritariamente a amostra é composta por pessoas com idade entre 18 e 25 anos (72,82\%) e em seguida, por indivíduos entre 36 e 45 anos (11,17\%).

Em relação à renda familiar, a maior representação da amostra é composta por turistas brasileiros que recebem entre $\mathrm{R} \$ 999,99$ (31,38\%) a $\mathrm{R} \$ 2999,99$ (31,38\%). Seguida por uma renda entre $\mathrm{R} \$ 3000,00$ a $\mathrm{R} \$ 4999,99(21,27 \%)$ e as demais rendas dividem-se em pequenas taxas de representação.

Tratando-se da quantidade de viagens realizadas com fins turísticos, a maioria da amostra realiza 01 viagem $(61,70 \%)$ anualmente. Na sequência 02 viagens $(19,14 \%)$. Encerrando, com relação a o quanto os turistas brasileiros gostam de viajar, com base nos dados da amostra apresenta-se que a maior parte dos mesmos gostam muito de viajar $(70,4 \%)$.

Diante do exposto, é notório que em média, os turistas brasileiros que conhecem ou desejam conhecer a Chapada das Mesas, representantes da amostra, possuem um perfil de jovem, de classe baixo-média, realizam de 1 a 2 viagens por ano com fins turístico e que gostam muito de viajar.

\subsection{Estatística descritiva das dimensões}

Na tabela 2 apresentam-se as dimensões de personalidade da marca de destinos turísticos (Ekinci, Sirakaya-Turk \& Baloglu, 2007; Hosany, Ekinci \& Uysal, 2006; Aaker, 1997; Kumar, 2016). Para isso, utilizou-se na estatística descritiva geral a média, desvio padrão, mínimo, quartil 1, mediana, quartil 3, e máximo.

Tabela 2 - Estatística descritiva geral

\begin{tabular}{l|c|c|c|c|c|c|c}
\hline \multicolumn{1}{c|}{ Variáveis } & Média & DP & Min & Q1 & Mdn & Q3 & Máx. \\
& & & & & & & \\
\hline Criterioso na escolha (y) & 4,17 & 1,03 & 1,00 & 3,00 & 5,00 & 5,00 & 5,00 \\
Convivialidade & 3,60 & 1,04 & 1,00 & 3,00 & 3,66 & 4,33 & 5,00 \\
Excitação & 4,08 & 0,93 & 1,00 & 3,33 & 4,33 & 5,00 & 5,00 \\
Sofisticação & 3.66 & 0,79 & 1,00 & 3,25 & 3,75 & 4,00 & 5,00 \\
Robustez & 3,07 & 0,86 & 1,00 & 2,66 & 3,00 & 3,66 & 5,00 \\
Ferocidade & 1,35 & 0,71 & 1,00 & 1,00 & 1,00 & 1,33 & 4,33 \\
Conformidade & 2,20 & 0,89 & 1,00 & 1,33 & 2,33 & 2,66 & 5,00 \\
\hline
\end{tabular}

Observa-se que as dimensões com as maiores médias foram Excitação $(M=4,08)$, que está associada à originalidade, ousadia e o quanto emocionante é o destino (Hosany, Ekinci, \& Uysal, 2006) e sofisticação (M=3,66) que refere-se ao elitismo (chique e alta classe) e estilo (elegante, sofisticada e glamorosa) (Aaker, 1997). Sugere-se este resultado se dá pelo fato da 
beleza natural das Chapadas das Mesas, e todas as experiencias emocionantes visuais e/ou construídas.

Em relação à menor média encontrada revela-se a dimensão Ferocidade $(M=1,35)$, que é associada a um destino violento e vulgar (Kumar, 2016). Os resultados evidenciam que esse fator não é comum à Chapada das Mesas, que proporciona um ambiente tranquilo diante de suas paisagens naturais.

Portanto observa-se que em média os turistas brasileiros preferem destinos que sejam emocionantes e possua originalidade à qual possa proporcionar recordações repletas de entusiasmo (Costa Junior \& Silva, 2020). E ainda, um local ao qual o turista perceba a elegância e sofisticação do seu destino. Os estudos vão de encontro ao de Ekinci, SirakayaTurk e Baloglu (2007), Hosany, Ekinci e Uysal (2006), Aaker (1997) e Kumar (2016).

Em relação à variável Y (Y = Como turista me considero criterioso na escolha de um destino turístico) $(\mathrm{M}=4,17)$, os dados revelam que o turista brasileiro em média consideram-se criteriosos na escolha de um destino turístico. De acordo com Hultman (et al., 2015) a satisfação final que o indivíduo deseja alcançar em relação a sua viagem turística, remete diretamente a obter exigência e ser criterioso ao escolher sua viagem.

\subsection{Análise multivariada}

Com o objetivo de identificar o grau de associação das dimensões de personalidade da marca de destinos turísticos (Ekinci, Sirakaya-Turk, \& Baloglu, 2007; Hosany, Ekinci \& Uysal, 2006; Aaker, 1997; Kumar, 2016) com a variável dependente (Y= Como turista me considero criterioso na escolha de um destino turístico).

Tabela 3 - Resultado da regressão

\section{ESCOLHA DE UM DESTINO TURÍSTICO}

\begin{tabular}{l|l|l}
\hline Dimensões da personalidade da marca de destinos & Coeficiente & $\mathbf{P}>|\mathbf{t}|$ \\
\hline Convivialidade & 0,10 & 0,24 \\
Excitação & 0,19 & 0,07 \\
Sofisticação & $-0,11$ & 0,38 \\
Robustez & $-0,12$ & 0,21 \\
Ferocidade & 0,09 & 0,38 \\
Conformidade & 0,14 & 0,19 \\
\hline Número de observações: & $\mathbf{1 8 8}$ \\
\hline \multicolumn{2}{c}{ Fonte: Elaborado pelos autores, 2020. ** e *** representam coeficientes significativos a 5\% e 1\%, } \\
\multicolumn{2}{r}{ respectivamente. }
\end{tabular}

De acordo com a Tabela 3, com o intervalo de confiança de até 95\%, os resultados da regressão não apresentam nenhuma relevância das dimensões da personalidade da marca de 
destinos com a variável dependente. Portanto, não foi possível identificar associações na escolha dos turistas brasileiros.

\subsection{Estatística descritiva das fontes de informações}

Com o objetivo de identificar o grau de relevância das fontes de informações utilizadas pelos turistas brasileiros na busca por um destino turístico, apresenta-se na Tabela 4 análises estatísticas em relação a: Agência de viagens, Mídia especializada em turismo, Guias de viagem, Documentários, Amigos e conhecidos, e Internet (Llodrà-Riera et al., 2015).

Tabela 4 - Estatística descritiva - fontes de informação ao escolher um destino turístico

\begin{tabular}{l|c|c|c|c|c|c|c}
\hline \multicolumn{1}{c|}{ Variáveis } & & & & & & \\
& Média & DP & Min & $\begin{array}{c}\text { Quartil } \\
1\end{array}$ & Mdn & $\begin{array}{c}\text { Quartil } \\
3\end{array}$ & Máx. \\
& & & & & & & \\
\hline Agências de viagens & & & & & & & \\
Mídia especializada em turismo & 3,64 & 1,37 & 1,00 & 3,00 & 4,00 & 5,00 & 5,00 \\
Guias de viagem & 3,87 & 1,38 & 1,00 & 3,00 & 5,00 & 5,00 & 5,00 \\
Documentários & 3,24 & 1,39 & 1,00 & 2,00 & 3,00 & 5,00 & 5,00 \\
Amigos e conhecidos & 4,30 & 1,10 & 1,00 & 4,00 & 5,00 & 5,00 & 5,00 \\
Internet & 4,19 & 1,29 & 1,00 & 4,00 & 5,00 & 5,00 & 5,00 \\
\hline
\end{tabular}

Fonte: Dados da pesquisa, 2020.

Diante dos dados apresentados, nota-se que "Amigos e Conhecidos" $(M=4,30)$ é a variável com a maior média (Sahin \& Baloglu, 2011), revelando que em média os turistas brasileiros são influenciados no momento de escolha de seu destino turístico pela opinião sobre o local e experiências vividas de seus amigos e familiares. Nota-se ainda que Internet $(M=4,19)$ é a segunda maior média.

Este resultado vai ao encontro dos estudos de Tomikawa (2009), onde o autor afirma que a internet é uma realidade, e o turismo foi o mais impactado por ela. Pela internet é possível descobrir novos destinos, saber o que eles oferecem e ainda, analisar feedbacks de turistas que já visitaram o local. O resultado também vai ao encontro da pesquisa de Costa Junior e Silva (2020).

No capítulo a seguir serão apresentadas as considerações finais. Nas quais será resgatado o objetivo da pesquisa, bem como as conclusões do estudo. Serão mencionadas ainda as contribuições e implicações teóricas e práticas, bem como as limitações e sugestão para futuras pesquisas. 


\section{CONSIDERAÇÕES FINAIS}

Diante do exposto, a pesquisa teve como estudo identificar o critério de escolha de turistas ao decidir pela Chapada das Mesas. Em particular, a presente pesquisa possui três objetivos específicos: perceber a relação entre o critério de escolha dos turistas e a personalidade da marca de destinos; verificar os traços que constituem a personalidade da marca de destinos na visão de turistas; e identificar o grau de relevância de diferentes fontes de informações utilizadas por turistas na busca por um destino turístico.

Os resultados sugerem que a Chapada das Mesas possui duas marcas relevantes na visão do turista, Excitação e Sofisticação: Neste sentido, sugere-se que a região é um local que chama a atenção pela beleza e originalidade. Corroborando com o fato de também ser um lugar elegante e glamoroso na visão dos turistas.

Para buscar maiores informações sobre o local de destino, os turistas buscam saber a opinião de amigos e familiares que já visitaram o local. Revela-se ainda a internet como um importante canal de informação, pois pode-se analisar as experiências de outros turistas nas fotos e comentários postados em sites como tripadvisor e trivago. Desta forma, os turistas buscam informações sólidas e concretas durante o planejamento das suas férias.

Esta pesquisa possui contribuição teórica para a literatura científica com relação à identificação de critérios atrativos para determinado publico turístico, e ainda contribui para os estudos sobre marketing turístico. Tais resultados obtidos pela pesquisa podem ser utilizados por gestores como fonte de informação para atrair seu público alvo. Pode-se ainda melhorar seu marketing turístico sabendo como e onde investir para maior atração de seus clientes.

Admite-se como limitação da pesquisa a falta de respostas por parte de turistas estrangeiros. Como um importante ponto turístico nacional, as Chapadas das Mesas atrai anualmente centenas de turistas de toda parte do mundo. Desta forma, a pesquisa não permite analisar este publico alvo.

Deste modo, sugere-se para futuras pesquisas a ampliação da amostra, replicando o questionário para turistas de outros países. Recomenda-se ainda que seja analisado o pós venda: a opinião dos turistas após a visita de seu destino, se suas expectativas foram alcançadas e quais aspectos podem ser melhorados em relação ao destino. 


\section{REFERÊNCIAS}

Aaker, J. L. (1997). Dimensions of brand personality. Journal of marketing research, 34(3), 347-356.

Aguilar, A. G., Guillén, M. J. Y., \& Roman, N. V. (2016). Destination brand personality: An application to Spanish tourism. International Journal of Tourism Research, 18(3), 210-219.

Caldwell, N., \& Freire, J. R. (2004). The differences between branding a country, a region and a city: Applying the Brand Box Model. Journal of brand management, 12(1), 50-61.

Chen, C. F., \& Phou, S. (2013). A closer look at destination: Image, personality, relationship and loyalty. Tourism management, 36, 269-278.

Costa Junior, L., \& Silva, L. C. (2020). Personalidade da Marca de Destinos e sua Relação com o Critério de Escolha dos Turistas Brasileiros. Revista Turismo em Análise, 31(1), 96114.

Crompton, J. L. (1979). An assessment of the image of Mexico as a vacation destination and the influence of geographical location upon that image. Journal of travel research, 17(4), 1823.

Echtner, C. M., \& Ritchie, J. B. (2003). The meaning and measurement of destination image. The Journal of tourism studies, 2(2), 2-12.

Ekinci, Y., \& Hosany, S. (2006). Destination personality: An application of brand personality to tourism destinations. Journal of travel research, 45(2), 127-139.

Ekinci, Y., Sirakaya-Turk, E., \& Baloglu, S. (2007). Host image and destination personality. Tourism Analysis, 12(5-6), 433-446.

Flores, L. C. S., Cavalcante, L. S., \& Raye, R. L. (2012). Marketing turístico: Estudo sobre o uso da tecnologia da informação e comunicação nas agências de viagens e turismo de Balneário Camboriú (SC, Brasil). Revista Brasileira de Pesquisa em Turismo, 6(3), 322-339.

Heung, V. C., \& Cheng, E. (2000). Assessing tourists' satisfaction with shopping in the Hong Kong special administrative region of China. Journal of Travel Research, 38(4), 396-404.

Hosany, S., Ekinci, Y., \& Uysal, M. (2006). Destination image and destination personality: An application of branding theories to tourism places. Journal of business research, 59(5), 638-642.

Hosany, S., Ekinci, Y., \& Uysal, M. (2007). Destination image and destination personality. International Journal of Culture, Tourism and Hospitality Research, 1(1), 62-81.

Hultman, M., Skarmeas, D., Oghazi, P., \& Beheshti, H. M. (2015). Achieving tourist loyalty through destination personality, satisfaction, and identification. Journal of Business Research, 68(11), 2227-2231.

Huybers, T. (2003). Domestic tourism destination choices - a choice modelling analysis. International journal of tourism research, 5(6), 445-459.

Jenkins, O. H. (1999). Understanding and measuring tourist destination images. International journal of tourism research, 1(1), 1-15. 
Krippendorf, J. (1989). Sociologia do turismo: para uma nova compreensão do lazer e das viagens. Rio de Janeiro: Civilização Brasileira.

Kubo, L., Costa, B. K., Cardoso, M. V., \& Ribeiro, T. D. L. S. A. (2017). A importância dos stakeholders para o brand equity e o valor da marca: um estudo de caso da agência/operadora de viagens. Revista de Turismo Contemporâneo, 5(2).

Kumar, V. (2016). Examining the role of destination personality and self-congruity in predicting tourist behavior. Tourism Management Perspectives, 20, 217-227.

Li, X., \& Kaplanidou, K. (2013). The impact of the 2008 Beijing Olympic Games on China's destination brand: A US-based examination. Journal of Hospitality \& Tourism

Research, 37(2), 237-261.

Llodrà-Riera, I., Martínez-Ruiz, M. P., Jiménez-Zarco, A. I., \& Izquierdo-Yusta, A. (2015). A multidimensional analysis of the information sources construct and its relevance for destination image formation. Tourism management, 48, 319-328.

Manosso, F. C., Ruiz, T. C. D., \& Nakatani, M. S. M. (2020). A aplicação do Storytelling nas pesquisas em Turismo: Uma Revisão Bibliométrica, Sistemática e Integrativa da Literatura. Revista de Turismo Contemporâneo, 8(2), 337-358.

Mazzon, J. A., \& Vera, L. A. N. (2008). A opinião dos turistas de negócios sobre a Imagem da Cidade de São Paulo. Revista Turismo em Análise, 19(3), 345-368.

Melo, F. V. S., \& Farias, S. A. (2014). Sustentabilidade como fator de identidade de destinos turísticos em websites: o consumidor se importa? BBR-Brazilian Business Review, 11(2), 143167.

Middleton, V. T., \& Clarke, J. (2002). Marketing de turismo: teoria \& prática. Elsevier.

Mihailovich, P. (2006). Kinship branding: A concept of holism and evolution for the nation brand. Place Branding, 2(3), 229-247.

Murphy, L., Benckendorff, P., \& Moscardo, G. (2007). Linking travel motivation, tourist selfimage and destination brand personality. Journal of travel \& tourism marketing, 22(2), 45-59.

Papadimitriou, D., Apostolopoulou, A., \& Kaplanidou, K. (2015). Destination personality, affective image, and behavioral intentions in domestic urban tourism. Journal of Travel Research, 54(3), 302-315.

Pezzi, E., \& Santos, R. J. (2012). A experiência turística e o turismo de experiência: aproximações entre a antropologia e o marketing. Anais do VII Seminário de pesquisa em turismo do Mercosul da Universidade de Caxias do Sul - UCS, Caxias do Sul, RS, Brasil.

Phillips, N., Lawrence, T. B., \& Hardy, C. (2004). Discourse and institutions. Academy of management review, 29(4), 635-652.

Pike, S. (2002). Destination image analyses: a review from 142 papers from 1973 to 2000. Tourism Management, 541-549.

Pimentel, E., Pinho, T., \& Vieira, A. (2006). Imagem da Marca de un Destino Turístico. Turismo-Visão e Ação, 8(2), 283-298. 
Rainisto, S. K. (2003). Success factors of place marketing: A study of place marketing practices in Northern Europe and the United States. Doctoral Dissertation, Helsinki University of Technology, Finland.

Sahin, S., \& Baloglu, S. (2011). Brand personality and destination image of Istanbul. Anatolia-An International Journal of Tourism and Hospitality Research, 22(01), 6988 .

Santana, G. G. (2008). Avaliação da adequação e eficácia de programas de marketing de destinos turísticos: uma análise de Balneário Camboriú-Santa Catarina, Brasil. Revista Turismo em Análise, 19(3), 424-449.

Shin, S. H., Yang, S. B., Nam, K., \& Koo, C. (2017). Conceptual foundations of a landmark personality scale based on a destination personality scale: Text mining of online reviews. Information Systems Frontiers, 19(4), 743-752.

Smith, V. L. (Ed.). (1989). Hosts and guests: The anthropology of tourism. University of Pennsylvania Press.

Tasci, A. D., \& Gartner, W. C. (2007). Destination image and its functional relationships. Journal of travel research, 45(4), 413-425.

Tomikawa, J. M. (2009). Marketing turístico e internet: uma análise dos sites oficiais de turismo dos estados brasileiros. Dissertação de Mestrado em Turismo, Universidade de Brasília, Brasília, DF, Brasil.

FORMATO PARA CITAÇÃO DESTE ARTIGO

SAMPAIO, E. C. S., \& COSTA JÚNIOR, L. (2021). Personalidade da marca de destinos, fontes de informações e sua relação com o critério de escolha da chapada das mesas por parte dos turistas. Revista de Turismo Contemporâneo, 9(2), 289-305. https://doi.org/10.21680/2357$\underline{8211.2021 v 9 n 2 I D 23730}$ 